\title{
A Randomized, Double-Blind, Placebo- Controlled Study Trial to Evaluate the Potential Effects of Naticol $®$, Fish Collagen Peptides on Symptoms of Sarcopenia in the Elderly
}

\author{
Susan M Tyree ${ }^{1}$, Gillian Dunn Galvin ${ }^{1}$, Christelle Bruno Bonnet ${ }^{2 *}$ and Ted G Dinan ${ }^{1,3}$ \\ ${ }^{1}$ Atlantia Clinical Trials, Ireland \\ ${ }^{2}$ Weishardt International, Rond-point Georges Jolimaitre, France \\ ${ }^{3}$ Department of Psychiatry, Cork University Hospital and University College Cork, Ireland
}

Submission: November 16, 2021; Published: December 07, 2021

*Corresponding author: Christelle Bruno-Bonnet, Weishardt International, Rond-point Georges Jolimaitre, BP 259, F-81305 Graulhet, France

\section{Abstract}

Background: Previous research has shown the potential effects of different doses of specific fish collagen peptides (Naticol@) on muscle mass and muscle function. In addition to these benefits, clinical studies have suggested that ingestion of specific fish collagen peptides (Naticolß) might also have beneficial effects on joint health such as osteoarthritis. Joint health, loss of muscle mass, and loss of muscle function are all symptoms experienced by elderly adults, and especially elderly adults suffering from sarcopenia, suggesting a possible role for Naticol ${ }^{\circ}$ to help to reduce these symptoms in this vulnerable population.

Aim: The aim of this study was to determine the effect of 24 weeks' supplementation of Naticol@ on symptoms of sarcopenia in an elderly population.

Methods: In a randomized, double blind, placebo-controlled, clinical trial 28 elderly adults consumed one 15g sachet of either Naticol ${ }^{\circledR}$ or the Placebo product (maltodextrin) mixed into 20cl of cold water daily before breakfast, for 24 weeks. Symptoms of sarcopenia were assessed using dual x-ray absorptiometry (DXA) to measure lean body mass, the Short Physical Performance Battery to assess physical performance, the handgrip strength assessment to assess upper body muscle function, and the chair stand test to assess lower body muscle function.

Results: This study showed that 24 weeks of supplementation with Naticol@ significantly improved symptoms of sarcopenia compared to placebo, by increasing lean muscle mass and increasing muscular function in the handgrip strength assessment, Short Physical Performance Battery, and Chair Stand Test.

Conclusion: The results of this study demonstrated that daily supplementation of Naticol@ (containing fish collagen peptides) in elderly adults can improve symptoms of Sarcopenia, increasing lean muscle mass and increasing both upper and lower body muscle function.

Keywords: Sarcopenia; Aging; Muscle mass; Muscle strength; Fish collagen peptides

\section{Introduction}

Sarcopenia was originally defined as the age-related loss of muscle-mass [1]; however, it was later updated also to include age-related loss of muscle function, such as muscle strength or physical performance [2,3]. While it is a normal characteristic of the aging process, it can predispose older adults to immobility, disability, and falls that can cause injury or death [1]. Independence among the elderly can be directly affected by sarcopenia-related reductions in muscle-mass and muscle-strength [2]. While the

personal impact of sarcopenia on individuals is concerning in its own right, the economic burden of sarcopenia and sarcopeniarelated hospitalizations is also substantial. Goates et al. [4] showed that the total estimated cost of hospitalizations in individuals with sarcopenia was US\$40.4 billion and skewed higher for Hispanic and non-Hispanic-Black women.

The current recommendations for the prevention or treatment of sarcopenia include physical exercise and nutritional 
interventions $[5,6]$, focusing particularly on resistance training and protein supplementation $[7,8]$ However, it is known that elderly adults do not respond as well to these regimens as younger adults due to anabolic resistance [9]. Additionally, it has been shown that as adults get older, their dietary protein intake declines progressively $[10,11]$. This decline can be due to a number of factors, including but not limited to changes in appetite, changes in preferences, reduced energy needs, and economic or cultural barriers (Volpi et al. 2012). One potential option for enhancing protein synthesis in older adults is through consumption of fish oils such as omega-3 polyunsaturated fatty acids (PUFAs), as omega-3 PUFAs have been shown to not only significantly enhance protein synthesis but also reduce protein breakdown [12]. Several research studies have shown potential for omega-3 fatty acids for preventing or minimizing the impact of sarcopenia in older adults by improving thigh muscle volume [13], increasing handgrip strength [13-15], suggesting that omega-3 PUFAs and other fish oils may protect against symptoms of sarcopenia.

To further explore the potential for fish oils to reduce symptoms of sarcopenia, this exploratory study was designed to evaluate the potential effects of daily oral doses of $15 \mathrm{~g}$ fish collagen peptides in an elderly population (55-80 years) on symptoms of sarcopenia, including muscle mass, muscle strength, and physical performance. The fish collagen peptides (Naticol@) studied were derived from hydrolyzed collagen, suitable for use in human food. Naticol ${ }^{\circledR}$ has been studied previously in human populations investigating the effect of daily oral consumption of Naticol ${ }^{\circledR}$ on osteoarthritis-related knee pain [16] as well as skin health such as skin firmness and hydration, and decreased visibility of wrinkles $[17,18]$.

This study aimed to determine the effect of 24 weeks' supplementation of $\mathrm{Naticol}{ }^{\circledR}$ on lean body mass, using dual x-ray absorptiometry (DXA); upper body muscle function, using a handgrip strength assessment for both dominant and nondominant hands; lower body muscle function, using a chair stand test; physical performance, using the Short Physical Performance Battery; along with assessing the safety of the product by assessing a safety blood panel and reporting any adverse events.

\section{Methods}

\section{Participants}

The sample comprised of 28 participants - 10 male and 18 female participants, aged 55-80 years who self-reported muscle loss, were randomized (Placebo $=10$; Naticol $\AA=18$ ). Participants were excluded from the study if they: were outside of the age range of 55-80 years; weighed greater than $85 \mathrm{~kg}$; were not capable of understanding the full nature, purpose, and possible risks/side effects of taking part in the study; were not in general good health; were menopausal; had a hypersensitivity/ allergy to the study materials; engaged in resistance training for more than 1 hour per week; participate in a structured exercise program; were unable to complete one chair stand; had experienced $>5$
$\%$ decrease in their total body weight in the last 3 months; used anti-inflammatory steroid medications, anticoagulants, anabolic steroids, corticosteroid, or estrogen use.

The site, investigator, protocol, informed consent form and other pertinent documents for this study were approved by the Clinical Research Ethics Committee of the Cork Teaching Hospitals, Lancaster Hall, 6 Little Hanover Street, Cork. All participants gave their written consent according to the Helsinki Declaration.

\section{Design and conduct of the study}

The study adopted a randomized, double-blind, placebocontrolled design, in which the effects of Naticol ${ }^{\circledR}$ (Fish Collagen Peptides) and placebo were assessed pre-dose and following 12 and 24 weeks ( \pm 6 days) of daily consumption of the intervention in a population of adult males and females, between 55 and 80 years old. The trial ran from May 9, 2018 (first participant, first visit) to December 12, 2018 (last participant last visit). 28 participants were randomized into one of two groups in a 2:1 ratio. 18 participants were randomly assigned to the active group (receiving Naticol@ , fish collagen peptides), and 10 participants were randomly assigned to the placebo group (receiving a maltodextrin placebo product).

The investigational productstudied in this trial was a $15 \mathrm{~g}$ sachet of Naticol@ fish collagen peptides, manufactured and released under the responsibility of Weishardt, which was provided to the Coordinator/Investigator in boxes containing single dose sachets. Participants consumed one $15 \mathrm{~g}$ sachet of either Naticol ${ }^{\circledR}$ or the Placebo product (maltodextrin) mixed into $20 \mathrm{cl}$ of cold water 15 minutes before breakfast, for 24 weeks. Naticol@ contains several amino acids such as proline, hydroxyproline, glycine, arginine, and others, as reported in previous trials [16], see Table 1 for a breakdown of amino acids present in Naticol@ as well as a summary of its nutritional value.

Participants were provided with 12 -week supply $( \pm 6$ days in case of loss/visit delay) of the investigational product at their baseline visit and instructed to consume one sachet daily with water prior to breakfast. Participants then returned for an interim visit at week 12, where they were given an additional 12-week supply ( \pm 6 days) of the investigational product to consume for the next 12 weeks, until they returned for their final visit at week 24 .

At each of the baseline, week 12, and week 24 visits, vitals (blood pressure, heart rate, body temperature), anthropometrics (weight, height, BMI, waist circumference), medication use, and any adverse events were recorded. Participants completed a short physical Performance Battery to assess lower body muscle function and physical performance at baseline, week 12, and week 24. A hand grip test to assess their upper body muscle function was completed at baseline and week 24. Body composition was assessed at baseline and week 24 to observe any changes in lean body mass. Participants were instructed to follow their normal diet and exercise routine and not consume any medications that may impact the outcome of the trial. 
Table 1: Naticol囚 Amino Acid Composition (percentage) and Nutritional Information.

\begin{tabular}{|c|c|}
\hline \multicolumn{2}{|c|}{ Typical Values per $100 \mathrm{~g}$} \\
\hline Energy & $1593 \mathrm{~kJ}(381 \mathrm{kcal})$ \\
\hline Protein & $95 \mathrm{~g}$ \\
\hline Moisture & $4.7 \mathrm{~g}$ \\
\hline Carbohydrates (of which sugars) & $0 \mathrm{~g}(0 \mathrm{~g})$ \\
\hline Total fats (of which saturated fats) & $0 \mathrm{~g}(0 \mathrm{~g})$ \\
\hline Ash (of which sodium) & $0.3 \mathrm{~g}(0.1 \mathrm{~g})$ \\
\hline Dietary Fibers & $0 \mathrm{~g}$ \\
\hline Vitamins & $0 \mathrm{~g}$ \\
\hline Amino Acids & Nutritional Information \\
\hline Glycine & 20.9 \\
\hline Proline & 12.6 \\
\hline Glutamic Acid & 11.6 \\
\hline Hydroxyproline & 10.5 \\
\hline Arginine & 8.9 \\
\hline Alanine & 8.3 \\
\hline Aspartic Acid & 5.1 \\
\hline Lysine & 3.5 \\
\hline Serine & 3.5 \\
\hline Threonine & 2.7 \\
\hline Leucine & 2.6 \\
\hline Phenylalanine & 2.3 \\
\hline Valine & 2 \\
\hline Isoleucine & 1.5 \\
\hline Hydroxylysine & 1.5 \\
\hline Histidine & 1.3 \\
\hline Methionine & 0.8 \\
\hline Tyrosine & 0.4 \\
\hline Cysteine + Cystine & 0.03 \\
\hline Total & 100 \\
\hline
\end{tabular}

\section{Statistical analysis}

A computer-generated schedule randomized participants to either the active (Naticol@) or placebo (maltodextrin) groups (2:1). All statistical analyses were carried out using SPSS Version 27 for Windows. All tests were two-sided and performed at the $5 \%$ level of significance. Cohen's d was used to determine the strength (standardized mean difference) of statistical results: No effect: $0 \leq$ $\mathrm{d}<0.2$; Small effect: $0.2 \leq \mathrm{d}<0.5$; Medium effect $0.5 \leq \mathrm{d}<0.8$; Large effect $d \geq 0.8$ [19]. Categorical parameters were summarized using absolute numbers. Numerical data were summarized by means of standard statistics (i.e., number of available data, mean, standard deviation, minimum, maximum). The difference between groups at baseline for continuous data was analyzed using unpaired t-tests for continuous data and for categorical data using Yate's Correction for Continuity Chi-Square test. The change in participant's measurements (DXA scan measurements, handgrip strength, SPPB) between treatment groups from baseline to the end of treatment were analyzed using a repeated-measures ANOVA (with the appropriate test of normality, homogeneity of variance, and sphericity carried out initially). Paired tests were used to determine within-group differences over time. 


\section{Measures}

\section{Assessment of lean body mass (DXA)}

Dual x-ray absorptiometry (DXA) was performed at the baseline visit and again at the final study visit (week 24) to assess any changes in lean body mass $(\mathrm{kg})$, this is considered one of the most common methods to estimate muscle mass [20].

\section{Assessment of handgrip strength}

A hand grip test was completed from baseline to end of study to provide an objective measure of isometric muscle strength in the upper extremities. Participants completed this test three times using both their dominant and non-dominant hand. Measures of full handgrip strength were taken using a calibrated hand dynamometer. The reliability and validity of hand strength evaluations strongly depend on the procedure and instrument used. Therefore, standardized positioning and instructions were carefully followed; the same test instrument was used for all testing; and the calibration of the dynamometer was checked regularly. For statistical analysis, the highest value of the three tests for the dominant hand was analyzed.

\section{Short physical performance battery test (including chair stand test)}

The SPPB test was completed at each study visit from baseline to end of study. The assessment includes three objective tests of balance and leg functionality: 1) a timed 4-meter walk at a normal pace using the best of two times; 2) five, timed, repeated chair stands measuring the time taken to complete five rises from a chair to a standing position as fast as possible with the arms crossed over the chest; and 3) three separate tests of standing balance, which include a side-by-side stand, a semi-tandem stand, and a tandem stand, with the maximum score awarded for successfully standing for 10 seconds in each individual test. The maximum score in each category is 4 and summing the three distinct test items creates the SPPB summary score. The possible range of scores is 0 to 12 , with higher scores denoting better balance and leg functionality.

\section{Assessment of product safety}

Adverse events reported by the participants were assessed by the clinical team and categorized according to Intensity, Relationship to study, Action taken, Outcome, Serious Adverse Event (SAE).

\section{Results}

There were no statistically significant differences in participants across treatment groups at baseline for demographic data, vitals or anthropometrics as determined by unpaired t-tests and chi-square test, see Table 2 . This finding validates the randomization method and indicates that there is no requirement to control for baseline differences in the subsequent endpoint analyses. All participants were Caucasian with a mean age of 62.5 years (55-76 years). The majority of the sample (>70 \%) were non -smokers and consumed alcohol. The mean BMI was 25.92, and the mean WHR was 0.87 . All participants had vitals (temperature, heart rate, blood pressure) within a non-clinical range (i.e., normal, or abnormal but not clinically significant). Both the Placebo and Naticol ${ }^{\circledR}$ groups showed similar baseline profiles, within normal ranges for the population, see Table 2 .

Table 2: Baseline participant demographics, along mean \pm SD [Min, Max] of vital signs, anthropometric measurements at baseline.

\begin{tabular}{|c|c|c|c|}
\hline & Placebo & Naticol $^{\circledR}$ & p-value \\
\hline $\mathrm{N}$ & 10 & $18^{*}$ & \\
\hline \multicolumn{4}{|c|}{ Demographics } \\
\hline Male: Female & $4: 06$ & $6: 12$ & 1 \\
\hline Age (years) & $61.8 \pm 6.18(55-76)$ & $62.9 \pm 5.58(55-72)$ & 0.638 \\
\hline \multicolumn{4}{|c|}{ Vitals } \\
\hline Temperature $\left({ }^{\circ} \mathrm{C}\right)$ & $36.2 \pm 0.21(35.8-36.6)$ & $36.3 \pm 0.23(35.9-36.6)$ & 0.912 \\
\hline Systolic BP (mmHg) & $120.1 \pm 8.03(104-131)$ & $126.3 \pm 10.79(107-148)$ & 0.126 \\
\hline Diastolic BP (mmHg) & $78.9 \pm 6.89(69-88)$ & $79.1 \pm 7.60(58-88)$ & 0.943 \\
\hline Pulse (bpm) & $66.2 \pm 8.85(56-81)$ & $64.9 \pm 7.00(49-76)$ & 0.682 \\
\hline \multicolumn{4}{|c|}{ Anthropometrics } \\
\hline Total Body weight $(\mathrm{kg})$ & $68.6 \pm 11.52(43.8-81.0)$ & $72.9 \pm 7.91(56.3-84.0)$ & 0.263 \\
\hline Height (m) & $1.67 \pm 0.07(1.55-1.78)$ & $1.7 \pm 0.08(1.52-1.77)$ & 0.779 \\
\hline BMI $\left(\mathrm{kg} / \mathrm{m}^{2}\right)$ & $24.6 \pm 2.87(18.23-27.70)$ & $26.7 \pm 3.38(22.81-33.67)$ & 0.115 \\
\hline Waist to Hip Ratio & $0.86 \pm 0.09(0.73-0.99)$ & $0.87 \pm 0.07(0.76-0.97)$ & 0.563 \\
\hline
\end{tabular}

${ }^{*} \mathrm{~N}=17$ for Height and BMI. Participant 089-014 was missing height so BMI could not be calculated. 
Mirroring the results in Table 2, there were no statistically significant differences in participants across treatment groups at baseline for primary or secondary endpoint data as determined by unpaired t-tests see Table 3. Repeated Measure ANOVAs were used to analyze between-group change from baseline to week 12 and baseline to week 24, See Table 3 . There was no statistically significant interaction between time ${ }^{*}$ product for any endpoint but statistically significant time effects. For this reason, additional paired t-tests for within-group change with Cohen's d effect size were run, see Table 4. Upon this further investigation, it was apparent that participants in the active group taking Naticol ${ }^{\circledR}$ experienced a statistically significant within-group change for lean mass (kg) and physical function (as measured by SPPB total score, Handgrip strength and Chair Stand Score) compared to the placebo group, see Table 4. The magnitude of the differences observed was compared using effect size-i.e., the standardized mean difference in measurements from baseline to week 24, with a larger difference, in the magnitude of the effect size statistics, found in the active Naticol ${ }^{\circledR}$ group than the placebo group for the four study endpoints. Due to the study's exploratory nature and the small sample size, comparing effect sizes is a reliable approach to inform the statistical power of future studies [21].

Table 3: Effect of 24 weeks' supplementation of Naticol®, on symptoms of sarcopenia related measurements, for participants that completed the study.

\begin{tabular}{|c|c|c|c|c|c|c|}
\hline & \multicolumn{3}{|c|}{ Placebo } & \multicolumn{3}{|c|}{ Naticol ${ }^{\circledR}$} \\
\hline & Baseline & Week 12 & Week 24 & Baseline & Week 12 & Week 24 \\
\hline $\mathrm{N}$ & 9 & - & 9 & 17 & - & 18 \\
\hline Total Lean Mass (kg) & $\begin{array}{c}43.39 \pm 9.29 \\
(28.01-56.43)\end{array}$ & - & $\begin{array}{c}42.92 \pm 9.52 \\
(27.31-57.00)\end{array}$ & $\begin{array}{c}43.42 \pm 7.37 \\
(32.07-56.90\end{array}$ & - & $\begin{array}{c}44.95 \pm 8.45 \\
(34.55-59.40)\end{array}$ \\
\hline $\mathrm{N}$ & 10 & 10 & 10 & 18 & 18 & 18 \\
\hline Handgrip Strength Test & $\begin{array}{c}21.60 \pm 6.75 \\
(14-32)\end{array}$ & & $\begin{array}{c}24.00 \pm 8.64 \\
(15-45)\end{array}$ & $\begin{array}{c}19.44 \pm 7.78 \\
(9-35)\end{array}$ & & $\begin{array}{c}22.94 \pm 7.28 \\
(15-42)\end{array}$ \\
\hline Total SPPB Score & $\begin{array}{c}11.8 \pm 0.63 \\
(10-12)\end{array}$ & $\begin{array}{c}11.9 \pm 0.32 \\
(11-12)\end{array}$ & $12.0 \pm 0.0(12-12)$ & $\begin{array}{c}11.33 \pm 0.84 \\
(9-12)\end{array}$ & $\begin{array}{c}11.67 \pm 0.49 \\
(11-12)\end{array}$ & $\begin{array}{c}11.83 \pm 0.38 \\
(11-12)\end{array}$ \\
\hline SPPB Chair Stand Score & $\begin{array}{c}3.80 \pm 0.63 \\
(2-4)\end{array}$ & $\begin{array}{c}3.90 \pm 0.32 \\
(3-4)\end{array}$ & $\begin{array}{c}4.00 \pm 0.00 \\
(4-4)\end{array}$ & $\begin{array}{c}3.33 \pm 0.84 \\
(1-4)\end{array}$ & $\begin{array}{c}3.67 \pm 0.49 \\
(3-4)\end{array}$ & $\begin{array}{c}3.83 \pm 0.38 \\
(3-4)\end{array}$ \\
\hline
\end{tabular}

There was a statistically significant time effect $p \leq 0.01$.

\section{Change in lean body mass (DXA)}

For improved health outcomes, an increase in Lean Mass(kg) is positive. Hence, a negative effect size (Baseline - Week 24) represents an improvement by $3.5 \%$ over the 24 weeks. The placebo group experienced no effect on their lean mass $(\mathrm{kg})(\mathrm{d}=$ $0.001 ; p=0.998$ ) from baseline to week 24. In contrast the active Naticol ${ }^{\circledR}$ group experienced a medium statistically significant by $3.5 \%$ within-group improvement in Lean Mass $(d=-0.53$; $\mathrm{p}=0.046$ ), see Table 4 .

\section{Change in handgrip strength}

In the Handgrip Strength Test, higher scores indicate greater upper body muscle function. Hence, a negative effect size (Baseline - Week 24) represents an improvement by $18 \%$ in function over the 24 weeks. The active Naticol@ group experienced a large statistically significant within group improvement in the Handgrip strength Test $(\mathrm{d}=-1.35 ; \mathrm{p}<0.001)$ while the placebo group didn't experience any statistically significant improvement $(p=0.176)$ from baseline to week 24, see Table 4.

\section{Change in chair stand test outcomes}

In the SPPB Chair Stand Test Subscale, higher scores indicate greater lower body muscle function [22]. Hence, a negative effect size (Baseline - Week 24) represents an improvement in function over the 24 weeks. The active $\mathrm{Naticol}{ }^{\circledR}$ group experienced a large statistically significant within group improvement in Chair Stand Test (respectively 10.2\% and 15\% improvement from baseline to week 12 and 24) while the placebo group didn't experience any statistically significant improvement in Chair Stand Test ( $p=0.343$ ) from baseline to week 12 and 24, see Table 4 .

\section{Change in short physical performance battery outcome}

In the SPPB, higher scores indicate better physical performance (Guralnik et al, 1994) [22]. Hence, a negative effect size (Baseline - Week 24) represents an improvement in physical performance over the 24 weeks. The active $\mathrm{Naticol}{ }^{\circledR}$ group experienced a large statistically significant within group improvement in SPPB total score (respectively $3 \%$ and $4.4 \%$ improvement from baseline to week 12 and 24) while the placebo group didn't experience any statistically significant improvement in Short Physical Performance battery Test $(\mathrm{p}=0.343)$ from baseline to week 12 and week 24 , see Table 4.

\section{Safety outcomes}

Twenty-one participants had taken prior concomitant and current medication, but none of these medications was excluded in this trial. Therefore, all twenty-one participants remained in the trial. No SAEs were reported during the course of this trial. 
Table 4: Paired Tests with Cohen's d, within groups effect size calculations on osteoarthritis related measurements from baseline to Week 24.

\begin{tabular}{|c|c|c|c|c|c|c|c|c|}
\hline & \multicolumn{4}{|c|}{ Placebo } & \multicolumn{4}{|c|}{ Naticol ${ }^{\circledR}$} \\
\hline & $\begin{array}{l}\text { p-value for } \\
\text { Baseline vs } \\
\text { Week } 12\end{array}$ & $\begin{array}{l}\text { Effect size } \\
\text { for Baseline } \\
\text { vs Week } 12\end{array}$ & $\begin{array}{l}\text { p-value for } \\
\text { Baseline vs } \\
\text { Week } 24\end{array}$ & $\begin{array}{l}\text { Effect size for } \\
\text { Baseline vs } \\
\text { Week } 24\end{array}$ & $\begin{array}{l}\text { p-value for } \\
\text { Baseline vs } \\
\text { Week } 12\end{array}$ & $\begin{array}{c}\text { Effect size } \\
\text { for Baseline } \\
\text { vs Week } 12\end{array}$ & $\begin{array}{l}\text { p-value for } \\
\text { Baseline vs } \\
\text { Week } 24\end{array}$ & $\begin{array}{l}\text { Effect size for } \\
\text { Baseline vs } \\
\text { Week } 24\end{array}$ \\
\hline \multicolumn{9}{|c|}{ Primary Endpoint } \\
\hline $\begin{array}{l}\text { Total Lean } \\
\text { Mass (kg) }\end{array}$ & & & 0.998 & 0.001 & - & - & 0.046 & -0.526 \\
\hline \multicolumn{9}{|c|}{ Secondary Endpoints } \\
\hline $\begin{array}{c}\text { Handgrip } \\
\text { Strength Test }\end{array}$ & & & 0.176 & -0.464 & & & $<0.001$ & -1.349 \\
\hline $\begin{array}{l}\text { Total SPPB } \\
\text { Score }\end{array}$ & 0.678 & -0.136 & 0.343 & -0.316 & 0.055 & -0.486 & 0.003 & -0.809 \\
\hline $\begin{array}{l}\text { SPPB Chair } \\
\text { Stand Score }\end{array}$ & 0.678 & -0.136 & 0.343 & -0.316 & 0.055 & -0.486 & 0.003 & -0.809 \\
\hline
\end{tabular}

\section{Discussion}

This double-blinded, placebo-controlled clinical study demonstrates the potential for specific fish collagen peptides to improve symptoms of sarcopenia in elderly adults. Specifically, the specific collagen peptides in the investigational product Naticol $®$, taken as a once-daily oral dose, resulted in improved lean mass, physical function (SPPB and Chair Stand tests), and strength (handgrip strength assessment). These findings align with previous findings assessing the effects of products containing collagen hydrolysates on symptoms experienced in elderly adults, including physical mobility and joint pain.

Previous studies investigating the impact of fish collagen peptide products on muscle mass $[13,14]$ tend to focus on a measure of thigh muscle volume rather than overall lean body mass measured by DXA, making direct comparisons with the present study difficult. However, findings from Smith et al. [13] showed that a 6-month treatment with fish-oil-derived n-3 PUFA therapy resulted in increased thigh muscle volume of approximately 6\% compared to placebo. This increase was reported as being less effective than exercise training therapies $[23,24]$, but similarly effective to hormone treatment therapies such as testosterone $[25,26]$ or growth hormone [26] for example. Therefore, when recommending fish collagen peptides such as Naticol $®$ to increase muscle mass, the outcomes would be greatly improved by including exercise training therapies alongside the Naticol $®$ supplementation, as shown by Rodacki et al. [23]. For future studies investigating this area, it would be recommended to also investigate thigh muscle volume specifically to enable the results to be directly compared to other relevant findings in previous clinical research studies.

The impact of Naticol® on physical function has previously been observed by Lacey et al. [16], in which an 8-week supplementation of $10 \mathrm{~g}$ daily Naticol@ showed a small, though not significant, improvement in the Total SPPB score and the
Chair Stand Test component of the SPPB. By extending the supplementation period of Naticol ${ }^{\circledR}$ from 8 weeks to 24 weeks of daily supplementation, the present study has further shown that this improvement continues and does indeed reach a significant effect level by 24 weeks of treatment. In addition to the SPPB and chair stand test, the handgrip strength test was used to measure upper body function. Previous studies, such as Smith et al. [13], have shown that, in a healthy population of older adults, a 6-month treatment with fish-oil-derived n-3 PUFA therapy resulted in an approximate $6 \%$ improvement in handgrip strength. Robinson et al. [15] also showed that handgrip strength in their elderly population was positively related to diet scores that reflected a high consumption of foods including fatty fish, vegetables, fruits, and wholemeal bread etc., supporting a link between dietary fish consumption and improvements in upper body muscle function.

Currently, the recommended course of treatment for adults experiencing symptoms of sarcopenia is to initiate exercise training therapies and improve nutrition to increase resistance training and increase dietary protein intake $[7,8]$. These interventions are considered less effective in elderly populations [9], so they may be improved by supplementing fish collagen peptides with products like Naticol®. While the mechanisms underlying the role of fish collagen peptides in changing muscle mass and muscle function are not fully understood, it is believed that they may impact both anabolic and catabolic pathways [13]. Animal studies have shown that oil-derived n-3 PUFA can increase the rate of muscle protein synthesis [27] and lessen the breakdown of muscle protein [28] - suggesting a dual role including protection of muscle tissue and the repair or synthesis of new muscle. These results could indicate that products containing fish collagen peptides such as Naticol ${ }^{\circledR}$ work to improve symptoms of sarcopenia, not only by replacing or repairing muscle tissue but also by providing a level of protection against future loss of muscle mass by attenuating the breakdown of muscle protein. 


\section{Juniper Online Journal of Case Studies}

\section{Conclusion}

The present study results suggest the potential for Naticol ${ }^{\circledR}$ to be used to improve muscle function and increase muscle mass in elderly persons suffering from symptoms of sarcopenia. The extension of the treatment period from 8 weeks in the previous study [16] to 24 weeks in the present study confirmed that the trend shown previously continued with the extended treatment, suggesting a six month or longer treatment with Naticol@ would significantly improve symptoms of sarcopenia in the elderly. As the main recommended course of treatment for sarcopenia includes physical exercise and nutritional interventions, the authors would recommend pairing daily supplementation of Naticol ${ }^{\circledR}$ with physical exercise training therapies to maximize the benefit of both forms of therapy.

\section{Conflict of Interest}

All financial, commercial, or other relationships that might be perceived by the academic community as representing a potential conflict of interest must be disclosed. If no such relationship exists, authors will be asked to confirm the following statement: The authors declare that the research was conducted in the absence of any commercial or financial relationships that could be construed as a potential conflict of interest.

\section{Author Contribution}

$\mathrm{CB}$ and TG contributed to the design of the study, GDG completed the statistical analysis of the results, SMT and GDG wrote the manuscript, and all authors discussed the results and commented on the manuscript.

\section{Funding}

The study was funded by Weishardt International Group (France) which provided the fish collagen peptides (Naticol@) assessed in this study.

\section{Acknowledgement}

The authors acknowledge the staff at Atlantia Clinical Trials Ltd. for their work in the completion of this clinical trial.

\section{References}

1. Rosenberg IH (1997) Sarcopenia: origins and clinical relevance. J Nutr 127(5 Suppl): 990s-991s.

2. Cruz-Jentoft AJ, Baeyens JP, Bauer JM, Boirie Y, Cederholm T, et al. (2010) Sarcopenia: European consensus on definition and diagnosis: report of the European Working Group on Sarcopenia in Older People. Age Ageing 39(4): 412-423.

3. Fielding RA, Vellas B, Evans WJ, Bhasin S, Morley JE, et al. (2011) Sarcopenia: an undiagnosed condition in older adults. Current consensus definition: prevalence, etiology, and consequences. International working group on sarcopenia. J Am Med Dir Assoc 12(4): 249-256

4. Goates S, Du K, Arensberg MB, Gaillard T, Guralnik J, et al. (2019) Economic Impact of Hospitalizations in US Adults with Sarcopenia. J Frailty Aging 8(2): 93-99.
5. Bauer J, Biolo G, Cederholm T, Cesari M, Cruz Jentoft AJ, et al. (2013) Evidence-based recommendations for optimal dietary protein intake in older people: a position paper from the PROT-AGE Study Group. J Am Med Dir Assoc 14(8): 542-559.

6. Beaudart C, Dawson A, Shaw SC, Harvey NC, Kanis JA, et al. (2017) Nutrition and physical activity in the prevention and treatment of sarcopenia: systematic review. Osteoporos Int 28(6): 1817-1833.

7. Cruz-Jentoft AJ, Landi F, Schneider SM, Zuniga C, Arai H, et al. (2014) Prevalence of and interventions for sarcopenia in ageing adults: a systematic review. Report of the International Sarcopenia Initiative (EWGSOP and IWGS). Age Ageing 43(6): 748-759.

8. Beaudart C, Rabenda V, Simmons M, Geerinck A, De Carvalho IA et al. (2018) Effects of protein, essential amino acids, B-hydroxy B-methylbutyrate, creatine, dehydroepiandrosterone and fatty acid supplementation on muscle mass, muscle strength and physical performance in older people aged 60 years and over. A systematic review on the literature. J Nutr Health Aging 22(1): 117-130.

9. Kumar V, Selby A, Rankin D, Patel R, Atherton P, et al. (2009) Agerelated differences in the dose-response relationship of muscle protein synthesis to resistance exercise in young and old men. J Physiol 587(1): 211-217.

10. Smeuninx B, Greig CA, Breen L (2020) Amount, Source and Pattern of Dietary Protein Intake across the Adult Lifespan: A Cross-Sectional Study. Front Nutr 7: 25.

11. Hone M, Nugent AP, Walton J, McNulty BA, Egan, B (2020) Habitual protein intake, protein distribution patterns and dietary sources in Irish adults with stratification by sex and age. J Hum Nutr Diet 33(4): 465-476.

12. Kamolrat T, Gray SR (2013) The effect of eicosapentaenoic and docosahexaenoic acid on protein synthesis and breakdown in murine C2C12 myotubes. Biochem Biophys Res Commun 432(4): 593-598.

13. Smith G, Julliand S, Reeds DN, Sinacore DR, Klein S, et al. (2015) Fish oil-derived n-3 PUFA therapy increases muscle mass and function in healthy older adults. Am J Clin Nutr 102(1): 115-122.

14. Yoshino J, Smith GI, Kelly SC, Julliand S, Reeds DN (2016) Mittendorfer, B. Effect of dietary n-3 PUFA supplementation on the muscle transcriptome in older adults. Physiol Rep 4(11): e12785.

15. Robinson SM, Jameson KA, Batelaan SF, Martin HJ, Syddall, et al. (2008) Diet, and its relationship with grip strength in community-dwelling older men and women: The Hertfordshire cohort study. J Am Geriatr Soc 56(1): 84-90.

16. Lacey S, Bonnet C, Seamans K, Doolan A (2019) Effect Size Statistics to Inform an Exploratory Analysis of a Double-Blinded, Randomised, Placebo Controlled Pilot Clinical Study to Evaluate the Efficacy of Naticol ${ }^{\circledR}$, Specific Fish Collagen Peptides to Alleviate Symptoms of Osteoarthritis in the Knee. JOJ Case Stud 10(2): 555783.

17. Duteil L, Queille-Roussel C, Maubert Y, Esdaile J, Bruno-Bonnet C, et al. (2016) Specific natural bioactive type 1 collagen peptides oral intake reverse skin aging signs in mature women. Journal of Aging Research \& Clinical Practice 5(2).

18. Sara S, Martin G, Sarah B, Raja AB, Genovese L (2015) An Overview of the Beneficial Effects of Hydrolysed Collagen as a Nutraceutical on Skin Properties: Scientific Background and Clinical Studies. The Open Nutraceuticals Journal 8: 29-42.

19. Cohen J. Statistical Power Analysis for the Behaviorial Sciences Routledge ISBN 1-134-74270.

20. Cawthon PM (2015) Assessment of Lean Mass and Physical Performance in Sarcopenia. J Clin Densitom 18(4):467-471.

21. Sullivan GM, Feinn R (2012) Using Effect Size-or Why the P Value Is Not Enough. J Grad Med Educ 4(3): 279-282. 
22. Guralnik JM, Simonsick EM, Ferrucci L, Glynn RJ, Berkman LF, et al. (1994) A short physical performance battery assessing lower extremity function: Association with self-reported disability and prediction of mortality and nursing home admission. Journal of Gerontology 49(2): M85-M94.

23. Rodacki CL, Rodacki AL, Pereira G, Naliwaiko K, Coelho I, et al. (2012) Fish-oil supplementation enhances the effects of strength training in elderly women. Am J Clin Nutr 95(2): 428-436.

24. Villareal DT, Chode S, Parimi N, Sinacore DR, Hilton T, et al. (2011) Weight loss, exercise, or both and physical function in obese older adults. N Engl J Med 364: 1218-1229.

25. Emmelot-Vonk MH, Verhaar HJ, Nakhai Pour HR, Aleman A, Lock TM, et al. (2008) Effect of testosterone supplementation on functional mobility, cognition, and other parameters in older men: a randomized controlled trial. JAMA 299(1): 39-52.
26. Giannoulis MG, Sonksen PH, Umpleby M, Breen L, Pentecost C, et al. (2006) The effects of growth hormone and/or testosterone in healthy elderly men: a randomized controlled trial. J Clin Endocrinol Metab 91(2): 477-484.

27. Smith GI, Atherton P, Reeds DN, Mohammed BS, Rankin D, et al. (2011) Dietary omega-3 fatty acid supplementation increases the rate of muscle protein synthesis in older adults: a randomized controlled trial. Am J Clin Nutr 93(2): 402-412.

28. Whitehouse AS, Smith HJ, Drake JL, Tisdale MJ (2001) Mechanism of attenuation of skeletal muscle protein catabolism in cancer cachexia by eicosapentaenoic acid. Cancer Res 61(9): 3604-3609.
This work is licensed under Creative Commons Attribution 4.0 License

DOI: 10.19080/JOJCS.2021.12.555850

\section{Your next submission with Juniper Publishers will reach you the below assets}

- Quality Editorial service

- Swift Peer Review

- Reprints availability

- E-prints Service

- Manuscript Podcast for convenient understanding

- Global attainment for your research

- Manuscript accessibility in different formats

( Pdf, E-pub, Full Text, Audio)

- Unceasing customer service

Track the below URL for one-step submission

https://juniperpublishers.com/online-submission.php 